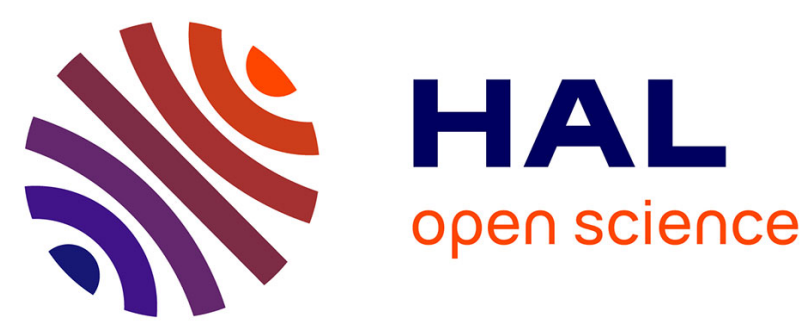

\title{
Complex Association of Sex Hormones on Left Ventricular Systolic Function: Insight into Sexual Dimorphism
}

Joe-Elie Salem, Lee Nguyen, Nadjib Hammoudi, Gisèle Preud'Homme, Jean-Sébastien Hulot, Monique Leban, Christian Funck-Brentano, Philippe Touraine, Richard Isnard, Anne Bachelot

\section{To cite this version:}

Joe-Elie Salem, Lee Nguyen, Nadjib Hammoudi, Gisèle Preud'Homme, Jean-Sébastien Hulot, et al.. Complex Association of Sex Hormones on Left Ventricular Systolic Function: Insight into Sexual Dimorphism. Journal of The American Society of Echocardiography, 2018, 31 (2), pp.231-240.e1. 10.1016/j.echo.2017.10.017 . hal-02384979

\section{HAL Id: hal-02384979 \\ https://hal.sorbonne-universite.fr/hal-02384979}

Submitted on 18 Dec 2019

HAL is a multi-disciplinary open access archive for the deposit and dissemination of scientific research documents, whether they are published or not. The documents may come from teaching and research institutions in France or abroad, or from public or private research centers.
L'archive ouverte pluridisciplinaire HAL, est destinée au dépôt et à la diffusion de documents scientifiques de niveau recherche, publiés ou non, émanant des établissements d'enseignement et de recherche français ou étrangers, des laboratoires publics ou privés. 


\section{Complex association of sex hormones on left ventricular}

\section{systolic function, insight into sexual dimorphism}

Running title: Influence of sex hormones on cardiac function

Joe-Elie Salem MD-PhD†§, Lee Nguyen $\mathrm{MD}^{\#} \dagger \S$, Nadjib Hammoudi MD-PhD ${ }^{\#} \S$, Gisèle Preud'homme MD§, Jean-Sebastien Hulot MD-PhD $\uparrow$, Monique Leban MD , Christian Funck-Brentano MD-PhD†, Philippe Touraine MD-PhD†, Richard Isnard MD-PhD* $\S$, Anne Bachelot MD-PhD* ; on behalf of CADIOHCS study group.

† AP-HP, Pitié-Salpêtrière Hospital, Department of Pharmacology and CIC-1421, F-75013 Paris, France; INSERM, CIC-1421 and UMR ICAN 1166, F-75013 Paris, France; Sorbonne Universités; UPMC Univ Paris 06, Faculty of Medicine, Department of Pharmacology and UMR ICAN 1166, F75013 Paris, France; Institute of CArdiometabolism and Nutrition (ICAN)

‡ AP-HP, Pitié-Salpêtrière Hospital, IE3M, Department of Endocrinology and Reproductive Medecine, and Centre de Référence des Maladies Endocriniennes Rares de la croissance et Centre des Pathologies gynécologiques Rares, and CIC-1421, F-75013 Paris, France

$\S$ Sorbonne Universités, UPMC Univ Paris 06, AP-HP, Pitié-Salpêtrière Hospital, Department of Cardiology-echocardiography unit, F-75013 Paris, France, UMR ICAN 1166, F-75013 Paris, France, Institute of CArdiometabolism and Nutrition (ICAN)

\#, * These authors contributed equally to this work

Reprints request and correspondence: Joe-Elie Salem, joe-elie.salem@aphp.fr, Centre d'Investigation Clinique Paris-Est, Hôpital La Pitié-Salpêtrière, Bâtiment Antonin Gosset, 4783 Bld de l'hôpital, 75651 Paris Cedex 13, Secretariat: +33 142178531, Fax: +33 142178532

World Count: 3989

Disclosure Statement: The authors have nothing to disclose

Acknowledgments: This study was supported by the French institutional PHRC 2010A00824-35 funding source and APHP, CIC Paris-Est. 
CARDIOHCS study group : Philippe Chanson, Sylvie Salenave, Sophie Christin Maitre,

Nathalie Bourcigaux, Michel Polak, Juliane Leger 


\begin{abstract}
Background. Normal values of left ventricular ejection fraction (LVEF) and absolute-values of global longitudinal strain (GLS) are lower in men than in women. Data concerning association of sex hormones levels on these left ventricular systolic function surrogates are scarce. We here report the association of sex hormones on systolic LV function in healthy subjects and patients with congenital adrenal hyperplasia (CAH) as a model of testosterone dysregulation.
\end{abstract}

Methods. Eighty-four adult (median age:27yo, IQR[23;36]) CAH patients (58 women) and 84 healthy subjects matched-paired for sex and age were prospectively included. Circulating concentrations of sex hormones were measured within 48 hours of an echocardiography with an assessment of LVEF and LV longitudinal, radial and circumferential strains.

Results. LVEF and GLS were higher in healthy women than in healthy men $(63.9 \pm 4.2 \%$ vs. $60.9 \pm 5.1 \%, \mathrm{p}<0.05$ and $20.0 \pm 1.9 \%$ vs. $17.9 \pm 2.4 \%, \mathrm{p}<0.001$, respectively) while there was no difference in LVEF or GLS between CAH women and men $(63.9 \pm 4.5 \%$ vs. $63.0 \pm 4.6 \%, \mathrm{p}=\mathrm{ns}$ and $19.4 \pm 2.2 \%$ vs. $18.3 \pm 1.8 \%, \mathrm{p}=\mathrm{ns}$, respectively). Bioavailable-testosterone levels were higher in women with $\mathrm{CAH}$ than in women controls $(0.08[0.04-0.14]$ vs. $0.16[0.04-$ $0.3] \mathrm{ng} / \mathrm{mL}, \mathrm{p}<0.001)$ and lower in men with $\mathrm{CAH}$ than in men controls $(2.3[1.3-3]$ vs. 2.9[2.5$3.4] \mathrm{ng} / \mathrm{ml}, \mathrm{p}<0.05)$. In men, LVEF and GLS were negatively correlated with bioavailabletestosterone levels $(\mathrm{r}=-0.3, \mathrm{p} \leq 0.05$ and $\mathrm{r}=-0.45, \mathrm{p}<0.01$; respectively), while mid-ventricular radial strain was positively correlated with bioavailable-testosterone level $(\mathrm{r}=0.38, \mathrm{p}<0.05)$. Absolute value of circumferential strain was positively correlated to FSH $(r=0.65, p<0.0001)$. Conclusions. Our data support that existence of sex dimorphism concerning left ventricular systolic cardiac function is significantly associated to testosterone levels.

Keywords: echocardiography, physiology, Sex Hormones, congenital adrenal hyperplasia, ventricular functions 


\section{Introduction}

In the healthy population, women have different reference values for most cardiac morphological and functional parameters. ${ }^{[1-5]}$ Men have larger and thicker left ventricles (LV) than women. ${ }^{[3,5]}$ This is associated with a differential pattern of the radial, circumferential and longitudinal components of its systolic function. ${ }^{[1,2,4,5]}$ Women and men tend to experience different types of heart failure (HF). Men are more likely to suffer from systolic dysfunction leading to HF with reduced ejection fraction (HFrEF) while women have higher rates of diastolic dysfunction leading to $\mathrm{HF}$ with preserved ejection fraction (HFpEF). ${ }^{[6]}$ Extensive data exist concerning the influence of sex hormones on heart repolarization ${ }^{[7]}$ but data concerning their influence on cardiac morphology and function, are scarce and disparate. ${ }^{[8,9]}$ Large epidemiological studies showed that low serum total-testosterone is a biomarker of cardiovascular mortality ${ }^{[9,10],[11]}$ and several small sample trials have shown promising results with testosterone for the treatment of HF ${ }^{[12-15]}$ However, administration of higher supraphysiological levels of testosterone have been associated with impaired diastolic function and post-infarction remodeling in clinical and preclinical models. ${ }^{[8,16-18]}$ Preclinical studies also have suggested that estrogens could prevent deterioration of cardiac function and remodeling after experimental myocardial infarction. ${ }^{[16]}$ The potential influence of other sex steroid hormones showing important role in heart repolarization such as progesterone, ${ }^{[7]}$ or gonadotropins regulating their production ${ }^{[19]}$, has not been studied. To further investigate these issues, we studied the association of main sex steroid hormones and gonadotropins on left ventricular morphology and function in healthy subjects and in a unique cohort of patients with congenital adrenal hyperplasia (CAH) due to $21 \alpha$-hydroxylase deficiency, a rare disease, used in our study as a model of testosterone dysregulation. CAH corresponds to a group of inherited autosomal recessive disorders that arises from defective steroidogenesis and results from a deficiency in one or several of the enzymes of cortisol biosynthesis. ${ }^{[20]}$ Deficiency of the $21 \alpha$-hydroxylase enzyme is the most common form of $\mathrm{CAH}$ and is characterized by 
cortisol and in some cases aldosterone deficiency associated with adrenal androgen excess and renin increase (Figure 1). ${ }^{[20]}$ Cortisol deficiency results in the ACTH-induced accumulation of substrate precursors such as $17 \mathrm{OH}$-progesterone and progesterone, and to increased secretion of adrenal androgens. ${ }^{[20]}$ Goals of treatment are to replace deficient hormones by glucocorticoids and in some cases mineralocorticoids, and control adrenal androgen excess. The optimal dose of glucocorticoid is that which fails to fully suppress 17 hydroxy $(\mathrm{OH})$-progesterone and maintains androgens in the mid-normal range. ${ }^{[20]}$ There is variability in ACTH suppression by this supplementation, leading to inter-individual variability in residual secretion of adrenal androgen and ultimately testosterone levels. In some patients, this leads to insufficient control of their disease, resulting in high levels of progesterone and adrenal androgens, disturbing gonadal axis with low LH and FSH release by the pituitary gland. ${ }^{[20]}$ Due to this variable response, we were expecting testosterone levels to be higher in $\mathrm{CAH}$ women and lower in $\mathrm{CAH}$ men than in sex-matched controls (see Figure 1 for further details).

The purpose of this work was first to determine if LV morphology and systolic function are different within and between men and women depending on CAH status. Secondly, our aim was to investigate for the first time the association of gonadotropins and sex steroid hormones with LV function to better decipher the normal structure and function of a beating heart. $^{[21]}$ 


\section{Methods}

\section{Study design}

Our work is ancillary to CARDIOHCS [NCT01807364], a multicenter prospective observational case-control study comparing early cardiovascular damages in adult men and women with $\mathrm{CAH}$ due to $21 \alpha$-hydroxylase deficiency and healthy controls. All patients gave written informed consent to participate and the study was approved by each hospital ethics committee.

\section{Study population}

Eighty-four young adults (58 women and 26 men) with CAH and 84 controls matchedpaired for sex, age $( \pm$ yyears) and smoking status (non-smoking, past smoking, active smoking) were prospectively included in CARDIOHCS study between 05/2011 and 08/2015. $\mathrm{CAH}$ adults included were diagnosed during childhood, proven by genetic testing confirming a 21 $\alpha$-hydroxylase deficiency. Exclusion criteria for CAH and healthy subjects were: known history of cardiovascular disease and pregnancy. Estradiol and/or progesterone contraception in the previous month was an exclusion criterion in healthy subjects and interruption was promoted in $\mathrm{CAH}$ patients. CAH patients were treated, as needed by their standard of care, with hydrocortisone or dexamethasone and some of them also received fludrocortisone.

\section{Study procedures and laboratory analysis}

CAH patients were referred to the study by three endocrinology unit (Pitié-Salpêtrière hospital, Paris; Saint-Antoine Hospital, Paris; Bicêtre Hospital, Le Kremlin-Bicêtre, France). $\mathrm{CAH}$ and healthy subjects were explored at the Centre d'Investigation Clinique Paris-Est (CIC-1421, Pitié-Salpétrière hospital, Paris). 
In the morning, before 10a.m., participants had a clinical examination including past medical history, physical examination with blood pressure measurement (with a standard sphygmomanometer), weight $(\mathrm{kg})$ and height $(\mathrm{m})$ measurements (body mass index: weight / height ${ }^{2}$ ), and electrocardiographic recording after at least 10 minutes of rest in the supine position. Included subjects were asked for chronic treatment intake. Blood samples for the determination of serum concentrations of 17-OH-progesterone, progesterone, testosterone, sex hormone-binding globulin (SHBG), estradiol, follicle-stimulating hormone (FSH), luteinizing hormone ( $\mathrm{LH})$ were collected in a dry tube and further assayed in the immunology laboratory of Pitié-Salpêtrière. Estradiol, progesterone, SHBG, testosterone, FSH and LH serum concentrations were assayed by chemi-luminescence (Modular-E170 Roche®) and 17-OHprogesterone by radioimmunoassay (KIP1409; DIAsource ImmunoAssays). Hexokinase/Glucose-6-phosphate dehydrogenase was used for the determination of fasting plasma glucose levels (Roche®). The methodology of electrocardiographic acquisition and measurements have been described elsewhere. ${ }^{[19]}$

\section{Echocardiography acquisition and analysis}

Transthoracic echocardiography was performed within 48 hours of clinical and biological evaluation. It was performed using a Vivid9 equipped with a M5S convex transducer (GE Healthcare; Horten, Norway) by one expert physician, blindly to clinical and biological data. Two-dimensional images, acquired with appropriate sector size and depth settings to achieve optimal visualization of all LV myocardium at the optimal frame rate of 50-80 frames/sec, were transferred to a workstation equipped with the EchopacPC software version 113 (GEVingmed-Ultrasound®; Horten, Norway). All examinations were analyzed off-line by one blinded senior cardiologists. All measurements were averaged over 3 to 6 cardiac cycles.

The following measurements were performed according to current guidelines: ${ }^{[22]} \mathrm{LV}$ internal diameter, inter-ventricular septal and posterior wall thicknesses at end diastole from 
M-mode. LV mass was derived according to Devereux formula. LV relative wall thickness was defined as 2 times LV wall thickness divided by LV diastolic diameter, measured at end diastole. LV wall thickness was calculated from the mean of posterior and inter-ventricular septal wall thicknesses. Left atrium maximal volume was measured using biplane method from apical four and two-chamber views. LV volumes and LV ejection fraction (LVEF) were measured using the biplane Simpson method. Measurements were indexed to body surface area as appropriate. Trans-mitral E wave velocity (E) was determined by Doppler-echography. Using pulsed tissue-Doppler mode, we acquired e', the mitral annular early diastolic velocity, on the four-chamber apical view, at septal level. Septal E/e' was then calculated and considered as a surrogate of left ventricular filling pressure. ${ }^{[23,24]}$ LV longitudinal, radial and circumferential strains were measured offline and blinded by one expert cardiologist, with the use of a standard commercially available software (Q-analysis, EchopacPC, GE-VingmedUltrasound®; Horten, Norway). Radial strain (RS) and absolute-value of circumferential strain (CS) were assessed on LV short-axis images at the papillary muscle level (midventricular) with speckle-tracking analysis. For all subjects, global longitudinal strain (GLS) values were derived from the average of LV apical 4-chamber and 2-chamber views, using speckle-tracking analysis (Figure 2). Three apical views were missing, or of insufficient quality in 43/168 (25.6\%) subjects, precluding use of 18 segments derived GLS in this study. Intra-observer variabilities of LVEF, LV strains and E/e' measurements in our laboratory are excellent (intra-class correlation coefficient $\geqslant 0.83$ ) and have been reported elsewhere. ${ }^{[24,25]}$

\section{Statistical analyses and power of the study}

Data are reported as mean \pm standard-deviations or median and interquartile range, as appropriate. Comparisons of quantitative variables were made by using Wilcoxon-paired ttest, Mann-Whitney tests, ANOVA (one-way, or two-way) with Tukey’s or Sidak's post-test, as appropriate. Qualitative variables were compared by using Chi2-test. Correlations between linear variables were assessed by calculating Pearson's or Spearman's coefficient (r), as 
appropriate by using Prism6 (GraphPad-software®, San-Diego, USA). Multivariable analysis was performed by ANCOVA (XLSTAT-software, Addinsoft@). Explanatory variables were selected to be tested in multivariable analysis only if they were associated to the dependent variable in univariate analyses, except for $\mathrm{CAH}$ status which was always tested. Best model was selected driven by Schwarz's Bayesian criterion. Statistical significance was accepted for $\mathrm{p} \leq 0.05$.

This study was sufficiently powered to detect the expected sex difference in absolute value of LVEF and GLS $(\approx 2-3 \%)$ within CAH and healthy subgroups. ${ }^{[1,2,4,5]}$ However, our study lacked power $(<70 \%)$ to study sex differences for absolute values of RS and CS. ${ }^{[1,2,4,5]}$ In details, the study had a $82 \%$ power to detect a LVEF difference of at least $3 \%$ between healthy men and any other of the 3 other groups by ANOVA (alpha risk=0.05; LVEF standarddeviation $=4 \%$, expected mean $\mathrm{LVEF}=65 \%$; considering $\mathrm{n}=25$ in $\mathrm{CAH}$ or healthy men subgroups, and 50 in each women subgroup). This study had a $87 \%$ power to detect a GLS difference of at least $|2 \%|$ between healthy men and any other of the 3 other groups by ANOVA (alpha-risk=0.05; GLS standard-deviation $=|2.5 \%|$, expected mean GLS $=|20 \%|$; considering $n=25$ in each men subgroup and 50 in each women subgroup).

In men with no exogenous sex hormone intake and delay $<48$ hours between hormonal sampling and echocardiography $(n=41)$, the study had a power of $80 \%$ to detect a significant correlation (with $\mathrm{r}>|0.41|$, alpha-risk=0.05) between hormones levels and LVEF or strain value.

We could not analyze the relations between sex hormone levels and echocardiographic parameter in the women subset, because they are characterized by very steep variation of hormonal levels during menstrual cycle, as opposed to men. ${ }^{[26]}$ In fact, most echocardiography were performed at least 24 to 48 hours after blood sampling. 


\section{Results}

\section{Clinical and hormonal evaluations}

The clinical characteristics of patients included in this study are shown in Table 1. In total, 168 adult subjects (median age: 27yo, IQR $[23 ; 36]$ ) of whom 116 were women (56 CAH and 56 healthy) and 52 men (26 CAH and 26 healthy) were included and available for analysis. Subjects had no known history of cardiovascular disease or treated hypertension. Only two CAH women were treated for dyslipidemia or diabetes.

The results of biological evaluations in women are shown in Table 2. Compared to healthy women, women with $\mathrm{CAH}$ had higher levels of progesterone (median and interquartile range: $2.7[1-8.5] \mathrm{ng} / \mathrm{mL}$ vs. $0.9[0.5-3] \mathrm{ng} / \mathrm{mL}, \quad \mathrm{p}<0.01)$ and bioavailable-testosterone $(0.16[0.04-$ $0.32] \mathrm{ng} / \mathrm{mL}$ vs. $0.08[0.04-0.14] \mathrm{ng} / \mathrm{mL}, \mathrm{p}<0.001)$.

The results of biological evaluations in men are shown in Table 2. Compared to healthy men, men with $\mathrm{CAH}$ had higher levels of progesterone $(1.0[0.4-3.6] \mathrm{ng} / \mathrm{mL}$ vs. $0.8[0.6-$ 1]ng/mL, $\mathrm{p}<0.05)$. In contrast, bioavailable-testosterone levels were lower in men with CAH than in healthy men $(2.3[1.3-3] \mathrm{ng} / \mathrm{mL}$ vs. $2.9[2.5-3.4] \mathrm{ng} / \mathrm{mL}, \mathrm{p}<0.01)$.

\section{Echocardiographic evaluations}

Heart morphological parameters such as initial thoracic aortic diameter, indexed LV telediastolic volume and indexed LV mass were not different between healthy men and CAH men nor between healthy women and $\mathrm{CAH}$ women. However, these parameters were significantly higher in men than in women $(\mathrm{p}<0.0001$, Table3).

LVEF and GLS were higher in healthy women than in healthy men $(63.9 \pm 4.2 \%$ vs. $60.9 \pm 5.1 \%, \mathrm{p}<0.05$ and $20.0 \pm 1.9 \%$ vs. $17.9 \pm 2.4 \%, \mathrm{p}<0.001$, respectively, Table 3 and Figure 3) while there was no difference in LVEF or GLS between CAH women and CAH men. LVEF was not significantly different between women (healthy or CAH) and CAH men 
(Figure3) while LVEF was $2.98 \pm 1.42 \%$ higher in women (healthy or $\mathrm{CAH}$ ) than in healthy men ( $p<0.05$, Figure3). E/e' was not significantly different among any subgroups (Table 3 and Figure3). Mean apical 4-chamber and 2-chamber LS were used to calculate GLS for all subjects in this study rather that the classical 18 segments derived GLS also taking into consideration apical 3-chamber, which was not computable in 43 patients. Of note, in the subset of patients in whom conventional 3 views derived GLS was available $(n=125)$, results presented in Table 3 were similar for those of GLS derived from mean 4 and 2 chambers.

\section{Correlation between LV systolic function and sex hormones in men}

Among the 52 men included in this study, 11 were excluded from analyses of correlations between echocardiographic parameters and hormonal levels, leaving 41 men (20 $\mathrm{CAH})$ for final analysis. Reason of exclusion were exogenous intake of hormonal drugs $(\mathrm{n}=2)$ and excessive delay $(>48 \mathrm{~h})$ between echocardiography and hormonal assays $(\mathrm{n}=9)$. According to univariable analysis in all available men (Supplemental Figure1), LVEF and GLS were negatively correlated with bioavailable-testosterone $(\mathrm{r}=-0.3, \mathrm{p} \leq 0.05, \mathrm{n}=41$ and $\mathrm{r}=-0.45$, $\mathrm{p}<0.01, \mathrm{n}=39$, respectively), while mid-ventricular radial strain (RS) was positively correlated with bioavailable-testosterone $(\mathrm{r}=0.38, \mathrm{p}<0.05, \mathrm{n}=40)$. LVEF, GLS and RS were not significantly associated with any other hormones sampled in this study, including ACTH and renin levels (Supplemental Table 1). Absolute value of CS was positively correlated to FSH $(\mathrm{r}=0.65, \mathrm{p}<0.0001, \mathrm{n}=40)$ and negatively correlated to progesterone $(\mathrm{r}=-0.33, \mathrm{p}<0.05, \mathrm{n}=40)$ (Supplemental Table 1). LVEF, GLS, RS and CS were not significantly associated to age, neither to systolic or diastolic blood pressure.

Multivariable analysis (ANCOVA) was performed in these men, integrating hormonal levels (bioavailable-testosterone for LVEF, GLS and RS; progesterone and FSH for CS), and disease status (healthy or $\mathrm{CAH}$ ). Bioavailable-testosterone remained negatively associated to LVEF $(\mathrm{r}=-0.27, \mathrm{p} \leq 0.05)$ and GLS $(\mathrm{r}=-0.43, \mathrm{p}<0.01)$ while bioavailable-testosterone was 
positively related to radial strain $(\mathrm{r}=0.35, \mathrm{p}<0.05)$ with no significant influence of $\mathrm{CAH}$ or healthy status. Additionally, FSH was still related to CS (r=0.67, p<0.0001). 


\section{Discussion}

The objective of this work was to investigate the association of sex, $\mathrm{CAH}$ disease and interactions between gonadotropins and sex steroid hormones on LV morphology and systolic function parameters in humans. Our study in adult healthy subjects and in $\mathrm{CAH}$ patients, overexpressing testosterone in women and under expressing testosterone in some men, is unique in that subjects were exposed to a wide range of sex steroid hormones and gonadotropins levels. We found that: 1/there is no major difference in heart function and morphology between well treated $\mathrm{CAH}$ and healthy adults; 2/In CAH patients, known sex differences persist for aortic size and LV volume but are blunted for LV systolic function. This finding seemed to be associated to sex hormones disturbance among CAH patients; 3/In men, we found that bioavailable-testosterone levels were correlated negatively with LVEF and absolute GLS, and positively with RS. Absolute CS correlated positively with FSH levels.

\section{Complex hormonal system regulating cardiac function}

Sex dimorphism concerning LV strain values reflecting the different component of cardiac systolic function have been well established by use of echocardiographic speckle-tracking technology $y^{[2,4,5]}$ and later, by magnetic-resonance-imaging. ${ }^{[1]}$ Radial component of systolic function is higher in men than in women, while longitudinal and circumferential component of systolic function are higher in women than in men, ${ }^{[1]}$ resulting in lower LVEF in men than in women. ${ }^{[5]}$ Our findings confirm these data and suggest that the higher level of bioavailabletestosterone in men contribute to the observed sexual dimorphism, being associated to increased radial strain and decreased longitudinal strain.

Sex steroid hormones secretions are constantly regulated by the hypothalamic-pituitary axis and, as occurs in other organs such as ovaries, testes or bones, ${ }^{[27]}$ the association of sex steroid hormones on LV function may be counterbalanced by the direct effects of gonadotropins. The rationale for a complex hormonal system regulating heart function is 
supported by the fact that RNA of sex steroids and gonadotropins receptors are expressed in the myocardium ${ }^{[7,8]}$ and it has been recently found positive associations between FSH and duration of cardiac repolarization in both sex. ${ }^{[19,28]}$ In our study, the positive association between FSH levels and CS is a new finding, further supporting the potential of gonadotrophins to alter myocardial function. We can hypothesize different effects of FSH and testosterone on cardiac systolic function depending on the multilayered cardiac fiber orientation constituted of cardiomyocytes with different electro physio-mechanical properties. ${ }^{[5,29,30]}$ M-cells, in mid myocardium, between the endocardial and epicardial layers of the heart, are histologically similar to epicardial and endocardial cells but electro physiologically and pharmacologically different. ${ }^{[29]}$ M-cells appear to be hybrid between Purkinje and ventricular cells and are involved in alteration of ventricular repolarization heterogeneity, a process known to be highly sex hormones sensitive. ${ }^{[7]}$ Tpeak-Tend duration, a validated electrocardiographic index of repolarization heterogeneity, ${ }^{[31,32]}$ has been recently and repeatedly associated with alteration of cardiac mechanical function. ${ }^{[33,34]}$ Leren et al. have shown that patients with cardiac congenital electrophysiological defects, such as patients with long QT syndrome, have reduced systolic function, also evaluated by strain. ${ }^{[35]}$

\section{Effect of testosterone administration in HF}

Several small sample studies have evaluated if, compared to placebo, testosterone improved exercise capacity in men ${ }^{[12]}$ or in women ${ }^{[15]}$ with stable chronic $\operatorname{HFrEF}^{[13,14]}$. Testosterone appeared to be a promising therapy to improve peak-oxygen consumption, 6-minute and shuttle walk-test, but there was no significant variation in LVEF. ${ }^{[13,17]}$ The overall beneficial effect of testosterone in HF is currently attributed to peripheral vasodilatation, improvement in general metabolism with increase of lean body and muscle mass, increase of hemoglobin and hematocrit levels and to a decrease in insulin resistance rather than to improvement of LV morphology and inotropy ${ }^{[12-15]}$. Of note, supra-therapeutic doses of anabolic-steroids, with 
chemical structure and properties related to $\mathrm{T}$, have been associated with a reduced cardiac function and adverse cardiac outcomes. ${ }^{[36-38]}$ Zwadlo et al., have recently demonstrated that finasteride, an anti-androgenic drug currently used in patients to treat prostate disease, reversed pathological cardiac hypertrophy and dysfunction in mice and was therefore proposed as a possible therapeutic option for heart failure in men. ${ }^{[39]}$ It was suggested that lower levels of androgens in women might explain why they have a better prognosis when experiencing aortic valve stenosis, hypertrophic cardiomyopathy, or heart failure, in comparison to men. ${ }^{[39,40]}$ Our findings are in line with the absence of a direct positive effect of testosterone on LVEF and further support the extra-cardiac effect of testosterone to explain symptoms improvement in HF patients. ${ }^{[11]}$

\section{Cardiac risk in CAH patients}

In the classical form of $\mathrm{CAH}$, steroid supplementation is mandatory to prevent adrenal crisis and suppress androgen excess. ${ }^{[20]}$ However, the therapeutic window is narrow, and CAH infants with steroid deficiency may develop a form of cardiomyopathy which is reversible after corticosteroid treatment. ${ }^{[41]}$ Supra-physiological doses of corticosteroid are often used to suppress androgen overproduction, and this may lead to iatrogenic Cushing's syndrome, a condition that is associated with insulin resistance, hypertension, and increased cardiac morbidity. ${ }^{[42],}$

In our cross-sectional cohort comparing $\mathrm{CAH}$ adults and age-matched healthy controls, we did not find any difference in heart morphology and systolic function at rest, between CAH and healthy subjects within sex groups. The sample size of this echocardiographic study in CAH patient is the largest reported so far. Our study supports the findings of other limited sample size studies ${ }^{[18,43,44]}$ that well treated and monitored CAH patients do not develop important morphological heart abnormalities at rest. 


\section{Limitations}

Women of child-bearing age, as opposed to men, are characterized by steep variation of hormonal levels during menstrual cycle ${ }^{[26]}$, precluding the realization of any association study with any phenotypic evaluation if hormonal sampling is not realized concomitantly. A dedicated study is needed to evaluate whether and how hormones may influence the different component of LV function in women.

One could also wonder if sex differences in LVEF found in our study could be explained by sex-related differences in LV volumes; although the data in Table 3 and from other large cohorts such as MESA and Framingham show that stroke volume in males are proportionally higher than in females. ${ }^{[45,46]}$

Of note, correlations found between hormonals levels and left systolic function parameters were significant but such amplitude of correlations are not expected to be relevant from a diagnostic perspective, but they do support a physiologic concept.

Conclusion. Our data support that existence of sex dimorphism concerning left ventricular systolic cardiac function is significantly associated to testosterone levels. 


\section{References}

[1] Andre F, Steen H, Matheis P, Westkott M, Breuninger K, Sander Y, et al. Age- and genderrelated normal left ventricular deformation assessed by cardiovascular magnetic resonance feature tracking. J Cardiovasc Magn Reson. 2015;17:25.

[2] Cheng S, Larson MG, McCabe EL, Osypiuk E, Lehman BT, Stanchev P, et al. Age- and sex-based reference limits and clinical correlates of myocardial strain and synchrony: the Framingham Heart Study. Circ Cardiovasc Imaging. 2013;6:692-9.

[3] Hayward CS, Webb CM, Collins P. Effect of sex hormones on cardiac mass. The Lancet. 2001;357:1354-6.

[4] Kocabay G, Muraru D, Peluso D, Cucchini U, Mihaila S, Padayattil-Jose S, et al. Normal left ventricular mechanics by two-dimensional speckle-tracking echocardiography. Reference values in healthy adults. Rev Esp Cardiol (Engl Ed). 2014;67:651-8.

[5] Shi J, Pan C, Kong D, Cheng L, Shu X. Left Ventricular Longitudinal and Circumferential Layer-Specific Myocardial Strains and Their Determinants in Healthy Subjects. Echocardiography. 2016;33:510-8.

[6] Komajda M, Lam CS. Heart failure with preserved ejection fraction: a clinical dilemma. Eur Heart J. 2014;35:1022-32.

[7] Salem JE, Alexandre J, Bachelot A, Funck-Brentano C. Influence of steroid hormones on ventricular repolarization. Pharmacol Ther. 2016;167:38-47.

[8] De Smet MA, Lapauw B, De Backer T. Sex steroids in relation to cardiac structure and function in men. Andrologia. 2017;49.

[9] Kloner RA, Carson C, 3rd, Dobs A, Kopecky S, Mohler ER, 3rd. Testosterone and Cardiovascular Disease. J Am Coll Cardiol. 2016;67:545-57.

[10] Oskui PM, French WJ, Herring MJ, Mayeda GS, Burstein S, Kloner RA. Testosterone and the cardiovascular system: a comprehensive review of the clinical literature. J Am Heart Assoc. 2013;2:e000272.

[11] Budoff MJ ES, Lewis CE, Mohler ER, Wenger NK, Bhasin S, Barrett-Connor E, Swerdloff RS, Stephens-Shields A, Cauley JA, Crandall JP, Cunningham GR, Ensrud KE, Gill TM, Matsumoto AM, Molitch ME, Nakanishi R, Nezarat N, Matsumoto S, Hou X, Basaria S, Diem SJ, Wang C, Cifelli D, Snyder PJ. Testosterone Treatment and Coronary Artery Plaque Volume in Older Men With Low Testosterone. JAMA. 2017;317:708-16.

[12] Caminiti G, Volterrani M, Iellamo F, Marazzi G, Massaro R, Miceli M, et al. Effect of long-acting testosterone treatment on functional exercise capacity, skeletal muscle performance, insulin resistance, and baroreflex sensitivity in elderly patients with chronic heart failure a double-blind, placebo-controlled, randomized study. J Am Coll Cardiol. 2009;54:919-27.

[13] Iellamo F, Volterrani M, Caminiti G, Karam R, Massaro R, Fini M, et al. Testosterone therapy in women with chronic heart failure: a pilot double-blind, randomized, placebocontrolled study. J Am Coll Cardiol. 2010;56:1310-6.

[14] Malkin CJ, Pugh PJ, West JN, van Beek EJ, Jones TH, Channer KS. Testosterone therapy in men with moderate severity heart failure: a double-blind randomized placebo controlled trial. Eur Heart J. 2006;27:57-64.

[15] Toma M, McAlister FA, Coglianese EE, Vidi V, Vasaiwala S, Bakal JA, et al. Testosterone supplementation in heart failure: a meta-analysis. Circ Heart Fail. 2012;5:31521.

[16] Cavasin MA, Sankey SS, Yu AL, Menon S, Yang XP. Estrogen and testosterone have opposing effects on chronic cardiac remodeling and function in mice with myocardial infarction. Am J Physiol Heart Circ Physiol. 2003;284:H1560-9. 
[17] Chung T, Kelleher S, Liu PY, Conway AJ, Kritharides L, Handelsman DJ. Effects of testosterone and nandrolone on cardiac function: a randomized, placebo-controlled study. Clin Endocrinol (Oxf). 2007;66:235-45.

[18] Marra AM, Improda N, Capalbo D, Salzano A, Arcopinto M, De Paulis A, et al. Cardiovascular abnormalities and impaired exercise performance in adolescents with congenital adrenal hyperplasia. J Clin Endocrinol Metab. 2015;100:644-52.

[19] Abehsira G, Bachelot A, Badilini F, Koehl L, Lebot M, Favet C, et al. Complex Influence of Gonadotropins and Sex Steroid Hormones on QT Interval Duration. J Clin Endocrinol Metab. 2016;101:2776-84.

[20] Bachelot A, Grouthier V, Courtillot C, Dulon J, Touraine P. MANAGEMENT OF ENDOCRINE DISEASE: Congenital adrenal hyperplasia due to 21-hydroxylase deficiency: update on the management of adult patients and prenatal treatment. Eur $\mathrm{J}$ Endocrinol. 2017;176:R167-R81.

[21] Buckberg GD, Weisfeldt ML, Ballester M, Beyar R, Burkhoff D, Coghlan HC, et al. Left ventricular form and function: scientific priorities and strategic planning for development of new views of disease. Circulation. 2004;110:e333-6.

[22] Lang RM, Badano LP, Mor-Avi V, Afilalo J, Armstrong A, Ernande L, et al. Recommendations for cardiac chamber quantification by echocardiography in adults: an update from the American Society of Echocardiography and the European Association of Cardiovascular Imaging. J Am Soc Echocardiogr. 2015;28:1-39 e14.

[23] Salem JE, Aissaoui N, Paluszkiewicz L, Morshuis M, Gummert J, Leprince P, et al. Impact of inodilator drugs on echocardiographic assessments of left ventricular filling pressure in patients with decompensated end-stage heart failure*. Crit Care Med. 2014;42:2508-17.

[24] Salem JE, Laveau F, Ceccaldi A, Funck-Brentano C, Hulot JS, Mameri A, et al. Impact of negative inotropic drugs on accuracy of diastolic stress echocardiography for evaluation of left ventricular filling pressure. Sci Rep. 2017;7:9537.

[25] Hammoudi N, Arangalage D, Djebbar M, Stojanovic KS, Charbonnier M, Isnard R, et al. Subclinical left ventricular systolic impairment in steady state young adult patients with sickle-cell anemia. Int J Cardiovasc Imaging. 2014;30:1297-304.

[26] Chabbert Buffet N, Djakoure C, Maitre SC, Bouchard P. Regulation of the human menstrual cycle. Front Neuroendocrinol. 1998;19:151-86.

[27] Wang J, Zhang W, Yu C, Zhang X, Zhang H, Guan Q, et al. Follicle-Stimulating Hormone Increases the Risk of Postmenopausal Osteoporosis by Stimulating Osteoclast Differentiation. PLoS One. 2015;10:e0134986.

[28] Canpolat U, Tokgozoglu L, Yorgun H, Baris Kaya E, Murat Gurses K, Sahiner L, et al. The association of premature ovarian failure with ventricular repolarization dynamics evaluated by QT dynamicity. Europace. 2013;15:1657-63.

[29] Antzelevitch C. M cells in the human heart. Circ Res. 2010;106:815-7.

[30] Sengupta PP, Korinek J, Belohlavek M, Narula J, Vannan MA, Jahangir A, et al. Left ventricular structure and function: basic science for cardiac imaging. J Am Coll Cardiol. 2006;48:1988-2001.

[31] Salem JE, Germain M, Hulot JS, Voiriot P, Lebourgeois B, Waldura J, et al. GENomE wide analysis of sotalol-induced $\mathrm{IKr}$ inhibition during ventricular REPOLarization, "GENEREPOL study": Lack of common variants with large effect sizes. PLoS One. 2017;12:e0181875.

[32] Antzelevitch C. T peak-Tend interval as an index of transmural dispersion of repolarization. Eur J Clin Invest. 2001;31:555-7.

[33] Oskouie SK, Prenner SB, Shah SJ, Sauer AJ. Differences in Repolarization Heterogeneity Among Heart Failure With Preserved Ejection Fraction Phenotypic Subgroups. Am J Cardiol. 2017;120:601-6. 
[34] Sauer A, Wilcox JE, Andrei AC, Passman R, Goldberger JJ, Shah SJ. Diastolic electromechanical coupling: association of the ECG T-peak to T-end interval with echocardiographic markers of diastolic dysfunction. Circ Arrhythm Electrophysiol. 2012;5:537-43.

[35] Leren IS, Hasselberg NE, Saberniak J, Haland TF, Kongsgard E, Smiseth OA, et al. Cardiac Mechanical Alterations and Genotype Specific Differences in Subjects With Long QT Syndrome. JACC Cardiovasc Imaging. 2015;8:501-10.

[36] Sullivan ML, Martinez CM, Gennis P, Gallagher EJ. The cardiac toxicity of anabolic steroids. Prog Cardiovasc Dis. 1998;41:1-15.

[37] Parker MW, Thompson PD. Anabolic-androgenic steroids: worse for the heart than we knew? Circ Heart Fail. 2010;3:470-1.

[38] Baggish AL, Weiner RB, Kanayama G, Hudson JI, Picard MH, Hutter AM, Jr., et al. Long-term anabolic-androgenic steroid use is associated with left ventricular dysfunction. Circ Heart Fail. 2010;3:472-6.

[39] Zwadlo C, Schmidtmann E, Szaroszyk M, Kattih B, Froese N, Hinz H, et al. Antiandrogenic therapy with finasteride attenuates cardiac hypertrophy and left ventricular dysfunction. Circulation. 2015;131:1071-81.

[40] Wu JC, Nasseri BA, Bloch KD, Picard MH, Scherrer-Crosbie M. Influence of sex on ventricular remodeling after myocardial infarction in mice. $\mathrm{J}$ Am Soc Echocardiogr. 2003;16:1158-62.

[41] Minette MS, Hoyer AW, Pham PP, DeBoer MD, Reller MD, Boston BA. Cardiac function in congenital adrenal hyperplasia: a pattern of reversible cardiomyopathy. J Pediatr. 2013;162:1193-8, 8 e1.

[42] Tritos NA, Biller BM, Swearingen B. Management of Cushing disease. Nat Rev Endocrinol. 2011;7:279-89.

[43] Green-Golan L, Yates C, Drinkard B, VanRyzin C, Eisenhofer G, Weise M, et al. Patients with classic congenital adrenal hyperplasia have decreased epinephrine reserve and defective glycemic control during prolonged moderate-intensity exercise. J Clin Endocrinol Metab. 2007;92:3019-24.

[44] Weise M, Mehlinger SL, Drinkard B, Rawson E, Charmandari E, Hiroi M, et al. Patients with classic congenital adrenal hyperplasia have decreased epinephrine reserve and defective glucose elevation in response to high-intensity exercise. J Clin Endocrinol Metab. 2004;89:591-7.

[45] Liu CY, Lai S, Kawel-Boehm N, Chahal H, Ambale-Venkatesh B, Lima JAC, et al. Healthy aging of the left ventricle in relationship to cardiovascular risk factors: The MultiEthnic Study of Atherosclerosis (MESA). PLoS One. 2017;12:e0179947.

[46] Chuang ML, Gona P, Hautvast GL, Salton CJ, Breeuwer M, O'Donnell CJ, et al. CMR reference values for left ventricular volumes, mass, and ejection fraction using computeraided analysis: the Framingham Heart Study. J Magn Reson Imaging. 2014;39:895-900. 


\section{Figures legends}

Figure 1. Schematic representation of patho-physiological processes (chronological steps numbered in green box) leading to sex hormones disturbance (increased in blue, decreased in red) in poorly controlled or untreated men (A) and women (B) with congenital adrenal hyperplasia (CAH). CAH due to 21-hydroxylase deficiency lead to a congenital inability to produce cortisol and aldosterone $\left(\mathrm{n}^{\circ} 1\right)$. Inefficient cortisol synthesis signals the hypothalamic-pituitary axis to increase ACTH $\left(\mathrm{n}^{\circ} 2\right)$. Consequently, the adrenal glands become hyperplastic and produce excess sex hormone precursors that do not require 21-hydroxylation processes, namely 17-hydroxy $(\mathrm{OH})$-progesterone, progesterone and $\Delta 4$ androstenedione $\left(\mathrm{n}^{\circ} 3\right)$. In men (A), $\Delta 4$-androstenedione and progesterone secreted in blood signals hypothalamic-pituitary axis to decrease LH/FSH ( $\left.{ }^{\circ} 4\right)$ and subsequently testosterone production by testis $\left(\mathrm{n}^{\circ} 5\right)$. In women $(\mathrm{B})$, these adrenal sex hormone precursors are further metabolized to active androgens by ovaries, i.e testosterone $\left(n^{\circ} 4\right)$ leading to decreased LH/FSH ( $n^{\circ}$ ). In both sexes, inefficient aldosterone synthesis decreases the reabsorption of sodium $\left(\mathrm{Na}^{+}\right)$by the tubular epithelial cells of the kidneys and increases renin levels $\left(\mathrm{n}^{\circ} 2^{\prime}\right)$. Supplementation of CAH patients by hydrocortisone or other corticosteroids, associated or not with fludrocortisone is generally required. Thus, there is variability in ACTH suppression by this supplementation, leading to inter-individual variability in residual secretion of adrenal sex hormone precursors and consequently testosterone levels.

Figure 2. Examples of measurement of apical 4 chamber longitudinal strain (A), apical 2 chamber longitudinal strain (B), mid-ventricular circumferential strain (C), and midventricular radial strain $(D)$. 
Figure 3. Two-way ANOVA results as a function of sex and disease status (CAH and healthy) of ascending thoracic aorta diameter(A), indexed left ventricular telediastolic volume(B), indexed left ventricular mass(C), left ventricular ejection fraction(D), global longitudinal strain(E), and septal E/e'(F). Values are represented as mean and standard error of the mean, in blue for $\mathrm{CAH}$ and in red for healthy subjects. Colored p-values represented are those computed for sex comparisons in CAH patients (in blue) and in healthy subjects (in red) by Tukey's or Sidak's post-test. 
Figure 1.

Figure 2.

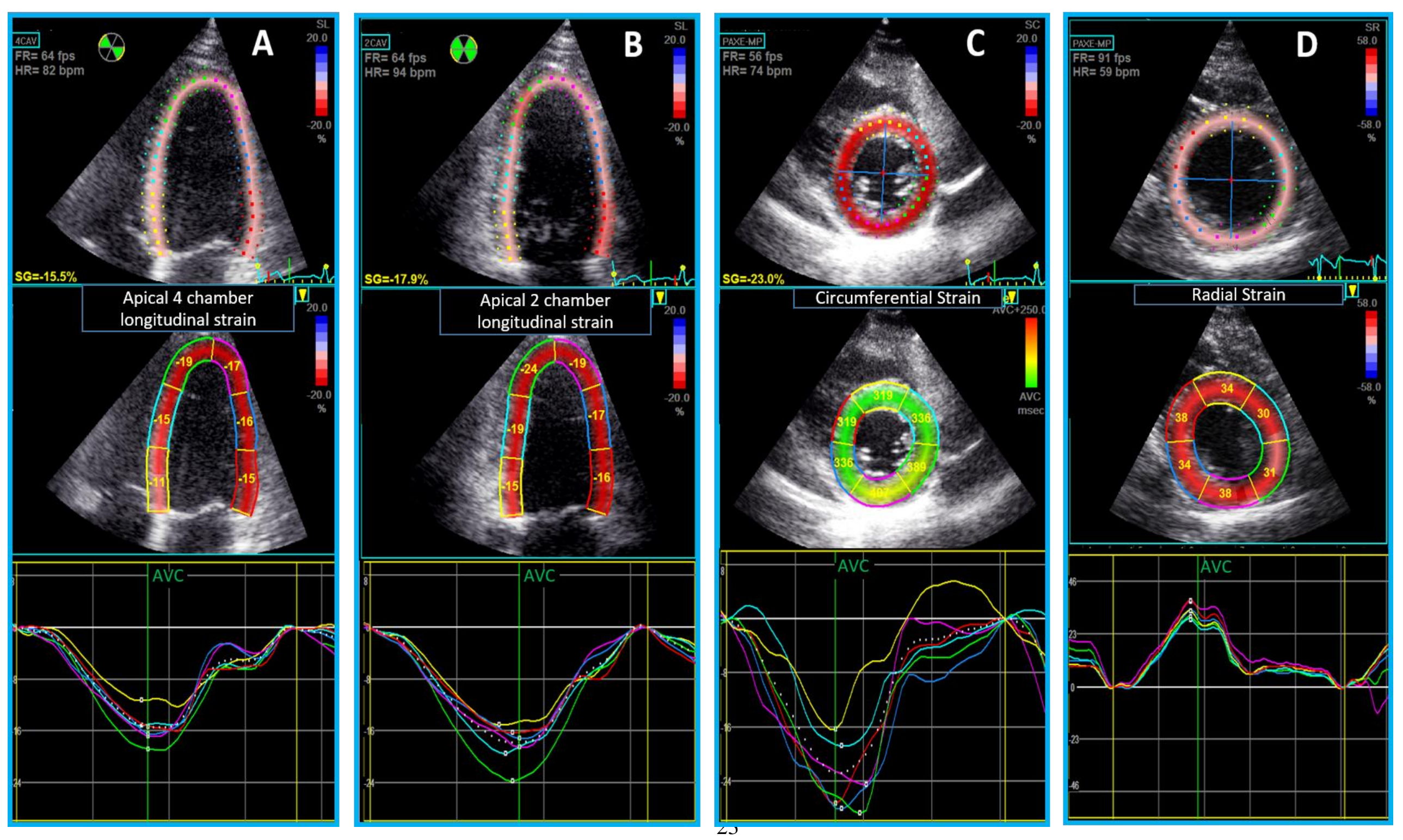


Figure 3.
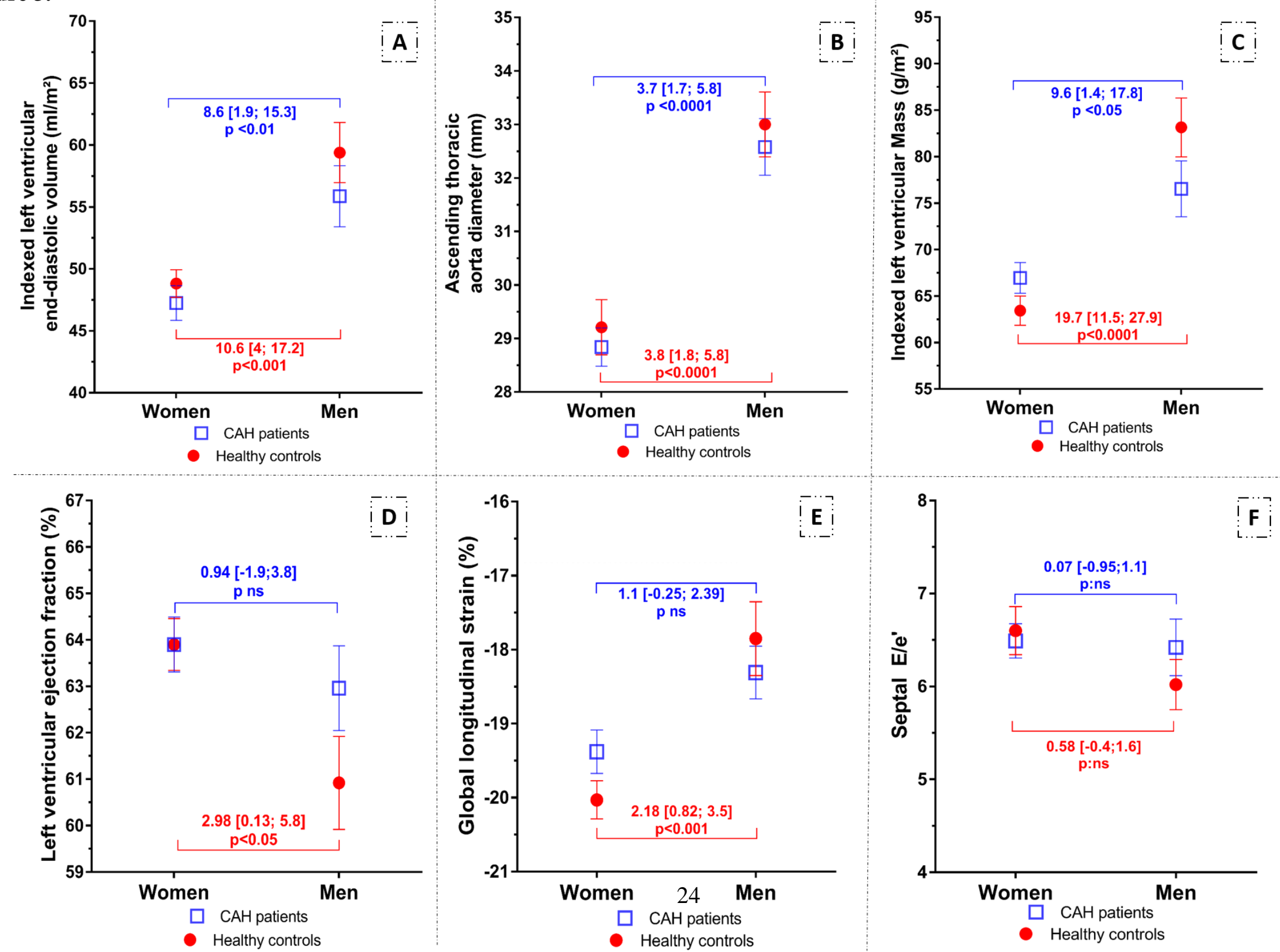


\section{Tables}

Table 1. Clinical characteristics of the patients included in the study

CAH males Healthy males CAH females $\begin{array}{r}\text { Healthy } \\ \text { females }\end{array}$

\begin{tabular}{|c|c|c|c|c|c|}
\hline Number of subjects & 26 & 26 & 58 & 58 & \\
\hline Age (years) & $28.8 \pm 7.9$ & $28.7 \pm 8.5$ & $30.7 \pm 9.1$ & $30.9 \pm 9$ & ns \\
\hline Body surface area $\left(\mathrm{m}^{2}\right)$ & $1.80 \pm 0.19^{* *, 7}$ & $1.90 \pm 0.15^{*, * *, F T}$ & $1.63 \pm 0.17^{*, t, H F}$ & $1.72 \pm 0.13^{* *, F}$ & $<0.0001$ \\
\hline BMI $>35 \mathrm{~kg} / \mathrm{m}^{2}$ & 0 & 0 & $3(5 \%)$ & 0 & ns \\
\hline $\mathrm{SBP}(\mathrm{mmHg})$ & $117.4 \pm 9.3^{*, * *}$ & $118.9 \pm 8.6^{*, * *}$ & $110.0 \pm 14^{f, f t}$ & $108.5 \pm 10.2^{f, f f}$ & $<0.0001$ \\
\hline $\mathrm{DBP}(\mathrm{mmHg})$ & $69.1 \pm 9.8$ & $69.6 \pm 7.2$ & $68.2 \pm 12.3$ & $68.3 \pm 7.9$ & ns \\
\hline Treated hypertension & $0(0 \%)$ & $0(0 \%)$ & $0(0 \%)$ & $0(0 \%)$ & ns \\
\hline $\begin{array}{c}\text { Cardiovascular disease in } \\
\text { family }(\%)\end{array}$ & $0(0 \%)$ & $1(4 \%)$ & $1(2 \%)$ & $5(9 \%)$ & ns \\
\hline $\begin{array}{l}\text { Current smoker / Past or non- } \\
\text { smoker }\end{array}$ & $\begin{array}{c}7 / 19 \\
(27 / 73 \%)\end{array}$ & $\begin{array}{c}7 / 19 \\
(27 / 73 \%)\end{array}$ & $\begin{array}{l}16 / 42 \\
(31 / 69 \%)\end{array}$ & $\begin{array}{l}16 / 42 \\
(31 / 69 \%)\end{array}$ & ns \\
\hline $\begin{array}{c}\text { Treated dyslipidemia or } \\
\text { diabetes }\end{array}$ & $0(0 \%)$ & $0(0 \%)$ & $2(3 \%)$ & $0(0 \%)$ & ns \\
\hline $\begin{array}{l}\text { Fasting glycemia } \\
\geq 7 \mathrm{mmol} / 1\end{array}$ & $0(0 \%)$ & $0(0 \%)$ & $0(0 \%)$ & $1(2 \%)$ & ns \\
\hline Fludrocortisone ( $\mu \mathrm{g} /$ day $)$ & $100[50-100]^{* *}$ & NA & $50[0-94]^{H t}$ & NA & $<0.01$ \\
\hline $\begin{array}{l}\text { Equivalent of hydrocortisone } \\
\text { (mg/day) }\end{array}$ & $30[20-40]^{* *}$ & NA & $20[10-25]^{f t}$ & NA & $<0.001$ \\
\hline
\end{tabular}

Abbreviations: BMI: body mass index; bpm: beats per minute; CAH: Congenital adrenal hyperplasia; cm: centimeter; kg: kilograms; SBP: systolic blood-pressure; DBP: diastolic blood-pressure; HR: heart rate; msec: millisecond; NA: not applicable

Statistics: ANOVA and Tukey's or Sidak's post-test or Mann-Whitney test for quantitative variables. Chi2 for qualitative variables. Not significant (ns) if $p \geq 0.05$. Quantitative variables are represented by the mean \pm standard deviation or median and interquartile range [-].

*Significant compared to healthy females; ${ }^{* *}$ Significant compared to CAH females;

${ }^{\ddagger}$ Significant compared to healthy males, ${ }^{+1}$ Significant compared to CAH males. 
Table 2. Biological evaluations in females and males

\begin{tabular}{|c|c|c|c|}
\hline \multicolumn{4}{|l|}{ FEMALES } \\
\hline & $\begin{array}{c}\text { CAH females } \\
\text { n: } \mathbf{5 8}\end{array}$ & $\begin{array}{c}\text { Healthy females } \\
\text { n: } 58\end{array}$ & $\mathbf{p}$ \\
\hline 17-OH progesterone $(\mathrm{ng} / \mathrm{mL})$ & $14.7[4.4-50.8]$ & $1.2[0.7-2.1]$ & $<0.0001$ \\
\hline Progesterone (ng/mL) & $2.7[1-8.5]$ & $0.9[0.5-3]$ & $<0.01$ \\
\hline SHBG (nmol/L) & $63[31-91]$ & $64[54-87]$ & ns \\
\hline Bioavailable-testosterone (ng/mL) & $0.16[0.04-0.3]$ & $0.08[0.04-0.14]$ & $<0.001$ \\
\hline Estradiol (pg/mL) & $65[42-162]$ & $87[40-170]$ & ns \\
\hline FSH (UI/L) & $5[3.2-6.4]$ & $6.4[4.1-8.3]$ & $<0.01$ \\
\hline LH (UI/L) & $5.5[2.8-8.3]$ & $6.7[5.1-12.8]$ & $<0.01$ \\
\hline $\operatorname{Renin}(\mathrm{pg} / \mathrm{mL})$ & $19.3[13.4-44]$ & $11.3[7.6-16.8]$ & $<0.001$ \\
\hline $\mathrm{ACTH}(\mathrm{pg} / \mathrm{mL})$ & $30.3[9-67.3]$ & $16.5[10.8-24.6]$ & $<0.0001$ \\
\hline \multicolumn{4}{|l|}{ MALES } \\
\hline & $\begin{array}{c}\text { CAH males } \\
\text { n: } 26\end{array}$ & $\begin{array}{c}\text { Healthy males } \\
\text { n: } 26\end{array}$ & $\mathbf{p}$ \\
\hline 17-OH progesterone $(\mathrm{ng} / \mathrm{mL})$ & $15.1[4.0-44.3]$ & $2[1.6-2.4]$ & $<0.0001$ \\
\hline Progesterone $(\mathrm{ng} / \mathrm{mL})$ & $1.0[0.4-3.6]$ & $0.8[0.6-1]$ & $<0.05$ \\
\hline SHBG (nmol/L) & $36.2[28.2-55]$ & $40.2[24.5-46.3]$ & ns \\
\hline Bioavailable-testosterone (ng/mL) & $2.3[1.3-3]$ & $2.9[2.5-3.4]$ & $<0.05$ \\
\hline Estradiol (pg/mL) & $29.5[19.8-32.6]$ & $28.3[24.7-37.3]$ & ns \\
\hline FSH (UI/L) & $3.9[2.3-7]$ & $3.4[2.6-5.2]$ & ns \\
\hline LH (UI/L) & $4.8[2-5.8]$ & $4.5[3.5-5.3]$ & ns \\
\hline Renin (pg/mL) & $26.0[15.9-44.6]$ & $13.1[10-16.5]$ & $<0.01$ \\
\hline ACTH (pg/mL) & $44.9[18-161.8]$ & $27.2[14.8-38]$ & $<0.01$ \\
\hline
\end{tabular}

Abbreviations: ACTH: Adrenocorticotropic hormone; FSH: follicle-stimulating hormone; LH: luteinizing hormone; SHBG: Sex hormone-binding globulin

Statistics: Wilcoxon-paired t-test for quantitative variables. Quantitative variables are represented by median and interquartile range [-]. Not significant (ns) if $p \geq 0.05$. 
Table 3. Echocardiographic characteristics of the patients included in the study

\begin{tabular}{|c|c|c|c|c|c|c|c|}
\hline & $\begin{array}{l}\text { Healthy females } \\
\qquad n=58\end{array}$ & $\begin{array}{c}\text { CAH females } \\
n=58\end{array}$ & $\begin{array}{c}\text { CAH males } \\
n=26\end{array}$ & $\begin{array}{l}\text { Healthy males } \\
\qquad n=26\end{array}$ & $\begin{array}{l}\text { p interaction } \\
\text { (sex-disease) }\end{array}$ & $\begin{array}{c}\mathrm{p} \text { sex } \\
\text { influence }\end{array}$ & $\begin{array}{l}\mathrm{p} \text { disease } \\
\text { influence }\end{array}$ \\
\hline Ascending aorta(mm) & $29.2 \pm 3.9^{t+t}$ & 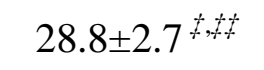 & $32.6 \pm 2.7^{* * * *}$ & $33.0 \pm 3.1^{*, * *}$ & ns & $<0.0001$ & ns \\
\hline \multicolumn{8}{|l|}{ LV morphology } \\
\hline LV end-diastolic volume index $\left(\mathrm{ml} / \mathrm{m}^{2}\right)$ & $48.8 \pm 8.5^{\text {thth }}$ & $47.3 \pm 10.7^{t+t h}$ & $55.9 \pm 12.3^{[1]^{*, * *}}$ & $59.4 \pm 12.4^{* * *}$ & ns & $<0.0001$ & ns \\
\hline LV end-systolic volume index $\left(\mathrm{ml} / \mathrm{m}^{2}\right)$ & $17.9 \pm 4.3^{*}$ & $17.1 \pm 4.6^{t, H}$ & $20.9 \pm 6.1^{[1]^{* *}}$ & $23.5 \pm 6.8^{* * * *}$ & ns & $<0.0001$ & ns \\
\hline LV wall thickness (mm) & $7.09 \pm 0.90^{f t t}$ & $7.12 \pm 0.82^{7+H}$ & $7.85 \pm 0.88^{*, * *}$ & $8.25 \pm 1.08^{*, * *}$ & ns & $<0.0001$ & ns \\
\hline LV mass index $\left(\mathrm{g} / \mathrm{m}^{2}\right)$ & $63.4 \pm 11.9^{f+t h}$ & $67.0 \pm 12.6^{t+t, t}$ & $76.5 \pm 15.4^{* * * *}$ & $83.2 \pm 16.1^{* * *}$ & $<0.05$ & $<0.0001$ & ns \\
\hline $\mathrm{LV}$ relative wall thickness & $0.30 \pm 0.04$ & $0.30 \pm 0.05$ & $0.31 \pm 0.04$ & $0.32 \pm 0.05$ & $\mathrm{~ns}$ & $<0.05$ & $\mathrm{~ns}$ \\
\hline \multicolumn{8}{|l|}{ LV diastolic function } \\
\hline Left atrium volume index $\left(\mathrm{ml} / \mathrm{m}^{2}\right)$ & $31.7 \pm 7.3$ & $29.5 \pm 6.0^{f}$ & $31.8 \pm 7.1^{[1]}$ & $34.9 \pm 7.7^{* *}$ & $\mathrm{~ns}$ & $<0.05$ & $<0.05$ \\
\hline $\mathrm{E} / \mathrm{e}^{\prime}$ & $6.6 \pm 1.9^{[4]}$ & $6.5 \pm 1.4$ & $6.4 \pm 1.5^{[3]}$ & $6.0 \pm 1.4$ & ns & $\mathrm{ns}$ & ns \\
\hline \multicolumn{8}{|l|}{ LV systolic function } \\
\hline LV Ejection fraction (\%) & $63.9 \pm 4.2^{*}$ & $63.9 \pm 4.5^{t}$ & $63.0 \pm 4.6^{[1]}$ & $60.9 \pm 5.1^{*, * *}$ & $\mathrm{~ns}$ & $<0.05$ & $\mathrm{~ns}$ \\
\hline 4C longitudinal strain $(\%)$ & $-19.9 \pm 2.2^{[2] \vec{f}, \vec{H}}$ & $-18.9 \pm 2.4^{[4] \#}$ & $-17.9 \pm 2.0^{[1] *}$ & $-17.2 \pm 2.6^{[1]^{* * * *}}$ & $\mathrm{~ns}$ & $<0.0001$ & ns \\
\hline 2C longitudinal strain $(\%)$ & $-20.6 \pm 2.2^{[3] \neq t+7}$ & $-19.8 \pm 2.4^{[4]}$ & $-18.7 \pm 2.1^{[1] *}$ & $-18.8 \pm 2.7^{[3] *}$ & ns & $<0.001$ & ns \\
\hline Global longitudinal strain (\%) & $-20.0 \pm 1.9^{[3]+\hbar t 7}$ & $-19.4 \pm 2.2^{[4] \#}$ & $-18.3 \pm 1.8^{[1] *}$ & $-17.9 \pm 2.4^{[3] * * * *}$ & $\mathrm{~ns}$ & $<0.0001$ & ns \\
\hline
\end{tabular}

Abbreviations: 4/2C: Apical four/two chambers; CAH: congenital adrenal hyperplasia; LV: left ventricular

Statistics: Differences between subgroups were assessed by two-way ANOVA (sex, disease) and Tukey's or Sidak's post-test. Quantitative variables are represented by the mean and standard deviation. Not significant (ns) if $p \geq 0.05$. Number of missing values within each subgroups is enclosed in square brackets $^{[x]}$, when needed. "Significant compared to healthy females; ${ }^{* *}$ Significant compared to CAH females; ${ }^{*}$ Significant compared to healthy males; ${ }^{H}$ Significant compared to CAH male 
Supplemental Table 1. Correlations (r) between hormonal levels and LV function parameters.

Significant results are in bold $(\mathrm{p}<0.05)$.

\begin{tabular}{|l|c|c|c|c|c|c|c|c|c|}
\hline \multicolumn{1}{|c|}{ Men } & $\begin{array}{c}17-\mathrm{OH} \text { PG } \\
(\mathrm{ng} / \mathrm{mL})\end{array}$ & $\begin{array}{c}\mathrm{PG} \\
(\mathrm{ng} / \mathrm{mL})\end{array}$ & $\begin{array}{c}\text { SHBG } \\
(\mathrm{nmol} / \mathrm{L})\end{array}$ & $\begin{array}{c}\text { Bio-T } \\
(\mathrm{ng} / \mathrm{mL})\end{array}$ & $\begin{array}{c}\text { EST } \\
(\mathrm{pg} / \mathrm{mL})\end{array}$ & $\begin{array}{c}\mathrm{LH} \\
(\mathrm{IU} / \mathrm{L})\end{array}$ & $\begin{array}{c}\text { FSH } \\
(\mathrm{IU} / \mathrm{L})\end{array}$ & $\begin{array}{c}\text { Renin } \\
(\mathrm{pg} / \mathrm{mL})\end{array}$ & $\begin{array}{c}\text { ACTH } \\
(\mathrm{pg} / \mathrm{mL})\end{array}$ \\
\hline $\begin{array}{l}\text { LV Ejection } \\
\text { Fraction (\%) }\end{array}$ & -0.09 & -0.16 & -0.16 & $-\mathbf{0 . 3 0}$ & -0.05 & 0.13 & 0.19 & -0.004 & -0.12 \\
\hline $\begin{array}{l}\text { Absolute Value } \\
\text { of GLS (\%) }\end{array}$ & -0.05 & 0.01 & 0.15 & $\mathbf{- 0 . 4 5}$ & 0.15 & -0.07 & 0.17 & -0.224 & -0.12 \\
\hline $\begin{array}{l}\text { Absolute Value } \\
\text { of RS (\%) }\end{array}$ & -0.02 & 0.19 & -0.30 & $\mathbf{0 . 3 8}$ & 0.17 & 0.02 & -0.16 & -0.119 & -0.04 \\
\hline $\begin{array}{l}\text { Absolute Value } \\
\text { of CS }(\%)\end{array}$ & -0.25 & $\mathbf{- 0 . 3 5}$ & 0.06 & 0.051 & 0.18 & $\mathbf{0 . 5 1}$ & $\mathbf{0 . 6 5}$ & -0.106 & -0.21 \\
\hline
\end{tabular}

Abbreviations: ACTH: Adrenocorticotropic hormone; Bio-T: Bioavailable testosterone; CS:

Circumferential Strain; EST: Estradiol; FSH: follicle-stimulating hormone; GLS: Global Longitudinal Strain; LH: luteinizing hormone; LV: Left ventricular; RS: Radial Strain; PG: Progesterone, SHBG: Sex hormone-binding globulin. 
Supplemental Figure 1. Correlations in men between levels of bioavailable-testosterone and LVEF (A), absolute value of global longitudinal strain (B), and mid-ventricular radial strain (C).

Correlations between levels of FSH and mid-ventricular absolute value of circumferential strain (D).
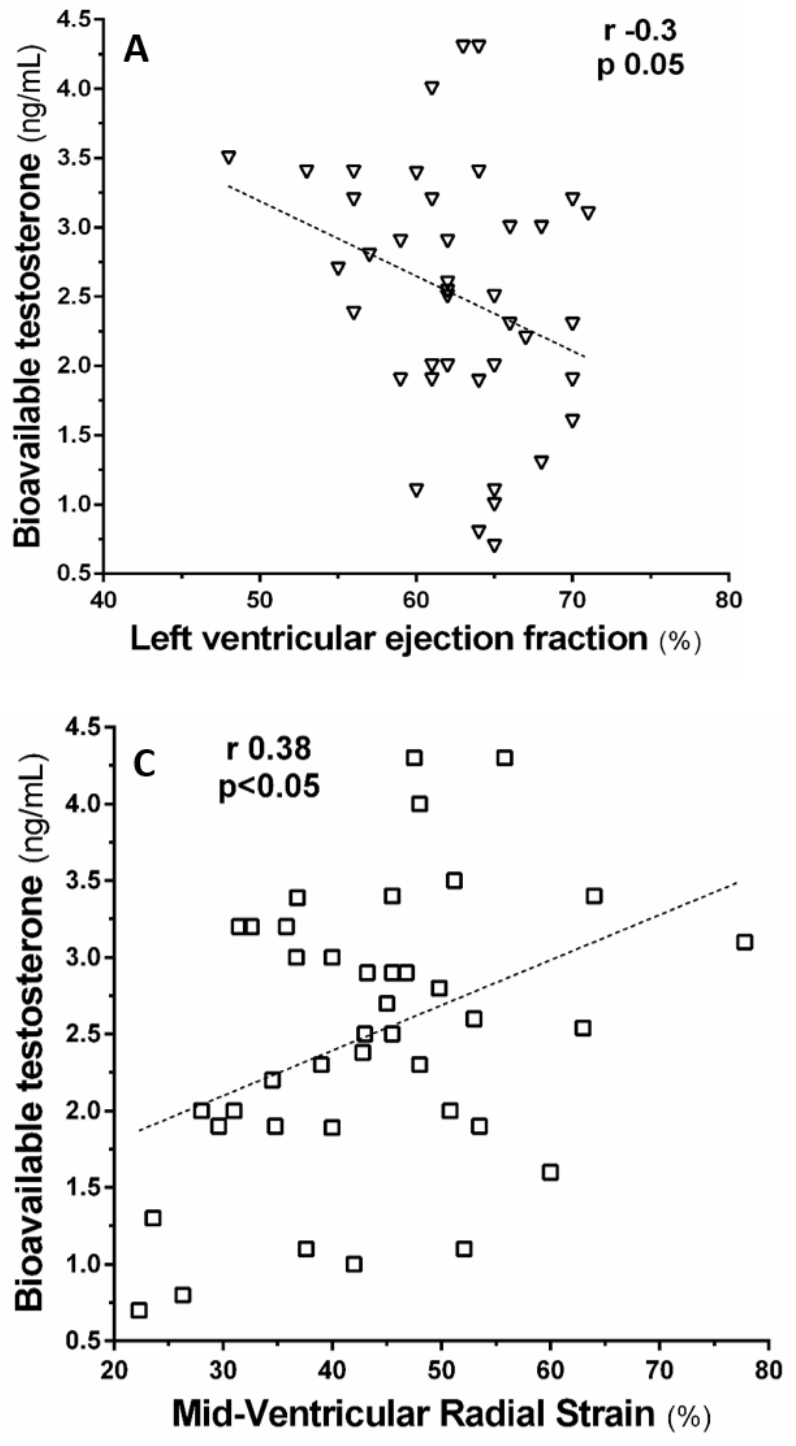
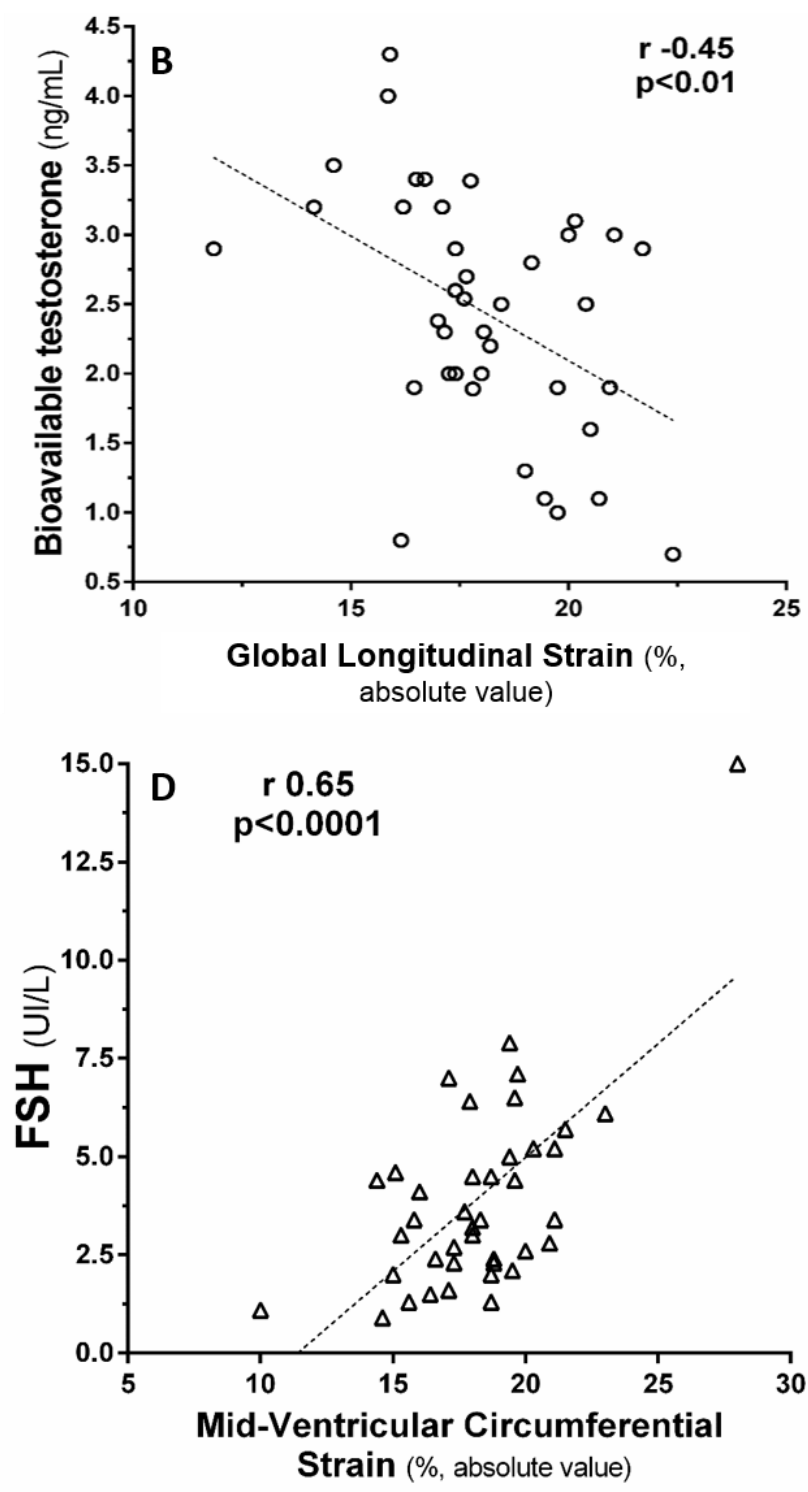